\title{
A corundum-rich inclusion in the Murchison carbonaceous chondrite
}

\author{
Miryam Bar-Matthews ${ }^{1,2}$ Ian D. Hutcheon ${ }^{3}$ Glenn J. MacPherson' \\ and LAWRENCE GROSSMAN ${ }^{1,3}$ \\ 'Dept. of the Geophysical Sciences, University of Chicago, 5734 South Ellis Avenue, Chicago, IL 60637 \\ ${ }^{2}$ Present address: Geological Survey of Israel, 30 Malchei Israel Street, Jerusalem, Israel \\ ${ }^{3}$ Enrico Fermi Institute, University of Chicago, 5640 South Ellis Avenue, Chicago, IL 60637
}

(Received January 5, 1981; accepted in revised form September 3, 1981)

\begin{abstract}
A corundum-hibonite inclusion, BB-5, has been found in the Murchison carbonaceous chondrite. This is the first reported occurrence of corundum as a major phase in any refractory inclusion, even though this mineral is predicted by thermodynamic calculations to be the first condensate from a cooling gas of solar composition. Ion microprobe measurements of $\mathrm{Mg}$ isotopic compositions yield the unexpected result for such an early condensate that ${ }^{26} \mathrm{Mg}$ excesses are small: $\delta_{N}{ }^{26} \mathrm{Mg}=7.0 \pm 1.6 \%$ for hibonite and $5.0 \pm 4.8 \%$ for cor undum, despite very large ${ }^{17} \mathrm{Al} /{ }^{44} \mathrm{Mg}$ ratios, 130 and $2.74 \times 10^{4}$, respectively. Within the errors, $\delta_{N}{ }^{26} \mathrm{Mg}$ does not vary over this exceedingly large range of ${ }^{27} \mathrm{Al} /{ }^{24} \mathrm{Mg}$ ratios. The extreme temperature required to melt this inclusion makes a liquid origin unlikely, except possibly by hypervelocity impact involving refractory bodies. If, instead, BB-5 is a direct gas-solid condensate, textural evidence implies that corundum formed first and later reacted to produce hibonite. In this model, BB-5's uniform enrichment in ${ }^{26} \mathrm{Mg}$ must be a characteristic of the reservoir from which it condensed. Because severe difficulties are encountered in making such a reservoir by prior decay of ${ }^{26} \mathrm{Al}$, nebular heterogeneity in magnesium isotopic composition is a preferred explanation.
\end{abstract}

\section{INTRODUCTION}

THERMODYNAMIC calculations predict that corundum $\left(\mathrm{Al}_{2} \mathrm{O}_{3}\right)$ is the first major phase to condense from a cooling gas of solar composition (Grossman, 1972); yet, remarkably, this phase is absent from all but one of the many high-temperature condensate inclusions studied so far in Type 3 carbonaceous (C3) chondrites. Fewer refractory inclusions have been studied in Type 2 carbonaceous (C2) chondrites, but it appears that many of these stopped equilibrating with the solar nebular gas at a higher temperature than those in C3's (Grossman et al., 1977; Macdougall, 1979). It is thus reasonable to expect that corundum will be more plentiful in refractory inclusions in C2's than in those in C3's. We describe here the first corundum-bearing inclusion discovered in a $\mathrm{C} 2$ chondrite and discuss its origin and possible relationships to other inclusions.

In many refractory inclusions, the magnesium isotopic composition differs from that of normal solar system matter in being enriched in ${ }^{26} \mathrm{Mg}$, known to be the product of in situ radioactive decay of nowextinct ${ }^{26} \mathrm{Al}$ (Lee et al., 1976; Hutcheon, 1981). Corundum-bearing inclusions would be expected to contain large enrichments of ${ }^{26} \mathrm{Mg}$ because they ought to pre-date other refractory inclusions and probably have higher ${ }^{27} \mathrm{Al} /{ }^{24} \mathrm{Mg}$ ratios than them. Thus, we also discuss here the results of ion microprobe analysis of the magnesium isotopic composition of this inclusion.

\section{TECHNIQUE}

Relatively little work has been done on refractory inclusions in C2's, mainly because they are much rarer and smaller than those in C3's, making them more difficult to find and dig uncontaminated from their matrix. After sev- eral years of relatively unproductive attempts to extract large numbers of such inclusions from Murchison in this way, we resorted to a different technique which proved to be eminently successful. It consists of multiple freeze-thaw cycles to disaggregate the meteorite into a fine powder and separation of the powder into density fractions with heavy liquids (MacPherson et al., 1980). In the $\rho>3.50$ fraction are abundant spheroidal and irregularly-shaped inclusions rich in blue hibonite (MacPherson et al., 1980; Tanaka et al., 1980). Because of its intensely blue color and unusually large size, $\sim 250 \mu \mathrm{m}$ in diameter, one such spherulc, BB5 , was split and made into a polished thin section which was viewed with an optical petrographic microscope and a scanning electron microscope (SEM).

The electron microprobe was used to gather chemical analyses using wavelength dispersive analysis. These were obtained using an ARL-EMX-SM automated electron microprobe, operated at $15 \mathrm{keV}$ accelerating voltage and $0.5 \mu \mathrm{A}$ beam current. Natural and synthetic minerals and glasses were used as standards.

A modified AEI IM-20 ion microprobe (Banner and Stimpson, 1975; Steele et al., 1977) was used for the $\mathrm{Mg}$ isotopic analyses. Secondary ions were generated by bombarding the surface of the sample with a mass-analyzed, ${ }^{16} \mathrm{O}^{-}$primary beam of $20 \mathrm{keV}$ impact energy and 2 to $3 \mathrm{nA}$ current, focussed into a 3 to $8 \mu \mathrm{m}$ diameter spot. Isotopic data were collected by step-scaming the spectrometer mag. net in the sequence ${ }^{26} \mathrm{Mg}^{25} \mathrm{Mg}^{24} \mathrm{Mg}^{26} \mathrm{Mg}$ using a computer-controlled, Hall-effect peak switching system. Isotopic ratios were calculated after each scan from the secondary ion intensities integrated over the central 35\% of each peak. Depending on a sample's Mg content, between 100 and 350 scans were averaged for each analysis and errors were calculated as two standard deviations of the mean. Every 20 scans, the sequence was automatically interrupted to measure the ${ }^{27} \mathrm{Al} /{ }^{24} \mathrm{Mg}$ ratio by scanning masses 27 and 24 . The mass spectrometer source slit was manually adjusted prior to these scans to keep the ${ }^{27} \mathrm{Al}^{+}$ count rate below $5 \times 10^{5}$ counts/second. For those samples containing $\mathrm{Ca}$, i.e., hibonite and anorthite in this study, the scan sequence was modified to include mass 20 every 5 scans. No corrections for system dead-time losses were necessary. 
The generation of polyatomic and multiply-charged secondary ions in the sputtering process (Bakale et al., 1975; Steele et al., 1980) creates potentially severe problems for low resolution ion probe isotopic analysis. To minimize the formation of hydride and hydrocarbon secondary ions (e.g., ${ }^{24} \mathrm{MgH}^{+}$and ${ }^{12} \mathrm{C}_{2} \mathrm{H}_{2}{ }^{+}$, respectively), the sample chamber was maintained at a pressure of $\sim 2 \times 10^{-8}$ torr and the ion extraction lenses were cooled to liquid nitrogen temperature. At the beginning of each day's run, the secondary ion mass spectrum of a terrestrial hibonite was scanned at a mass resolution of $\sim 3000$ to check for possible interfering species in the region between masses 27 and 22 . The only interference detected was ${ }^{48} \mathrm{Ca}^{++}$at mass 24 . Specifically, the following interferences were absent: ${ }^{48} \mathrm{Ti}^{++}$at mass 24 , ${ }^{50} \mathrm{Ti}^{++}$and ${ }^{24} \mathrm{MgH}^{+}$at mass 25 and ${ }^{12} \mathrm{C}_{2} \mathrm{H}_{2}{ }^{+}$at mass 26. The upper limit to the fractional contribution from these species to the $\mathrm{Mg}^{+}$signals is $2 \times 10^{-4}$. Isotopic data were collected at mass resolutions between 200 and 300, for which ${ }^{24} \mathrm{Mg}^{+}$and ${ }^{48} \mathrm{Ca}^{++}$were not resolved. The ${ }^{48} \mathrm{Ca}^{++}$ correction was calculated from the ${ }^{40} \mathrm{Ca}^{++}$signal at mass 20 , assuming ${ }^{48} \mathrm{Ca} /{ }^{40} \mathrm{Ca}=1.9078 \times 10^{-3}$ (Russell et al., 1978). The maximum correction to the signal at mass 24 was $0.5 \%$.

The background in the region of the three $\mathrm{Mg}$ peaks was uniformly flat and less than 0.1 counts/second for all samples regardless of the $\mathrm{Al} / \mathrm{Mg}$ ratio. The background was evaluated before each analysis under the same operating conditions with which isotopic data were acquired and never exceeded 0.1 counts/second, less than $1 \times 10^{-3}$ of the ${ }^{25} \mathrm{Mg}^{+}$ signal in BB-5 corundum, the most $\mathrm{Mg}$-poor sample. The absence of any diffuse background or specular scattered peaks is clearly shown in the mass spectrum of Yogo Gulch sapphire (Fig. 1). To check for background peaks which coincide exactly with the $\mathrm{Mg}$ peaks, we analyzed a synthetic $\mathrm{Al}_{2} \mathrm{O}_{3}$ sample using the same analytical conditions. A peak of 50 counts/second was observed at mass 24 , while the intensity at masses 25 and 26 was less than 0.5 counts/ second. Further analysis of the spectrum revealed that the sample contained $\mathrm{Ti}$ and that the mass 24 peak was most likely ${ }^{48} \mathrm{Ti}^{++}$. The ratio of the intensities at masses 25 and 26 was consistent with the normal ${ }^{25} \mathrm{Mg} /{ }^{26} \mathrm{Mg}$ isotope ratio and these small signals probably indicate a small amount of $\mathrm{Mg}, \sim 80 \mathrm{ppb}$, in the $\mathrm{Al}_{2} \mathrm{O}_{3}$. The ${ }^{27} \mathrm{Al}^{+}$signal from the synthetic $\mathrm{Al}_{2} \mathrm{O}_{3}$ was $\sim 10^{8}$ counts/second and, while the mass 27 peak was slightly broadened at the base with tails of $\sim 30$ counts/second at 0.1 mass units on either side of mass 27 , the background returned to $<0.1$ counts/second for a displacement of 0.3 mass units. No background corrections were applied to the data.

The analysis of terrestrial minerals had shown that the

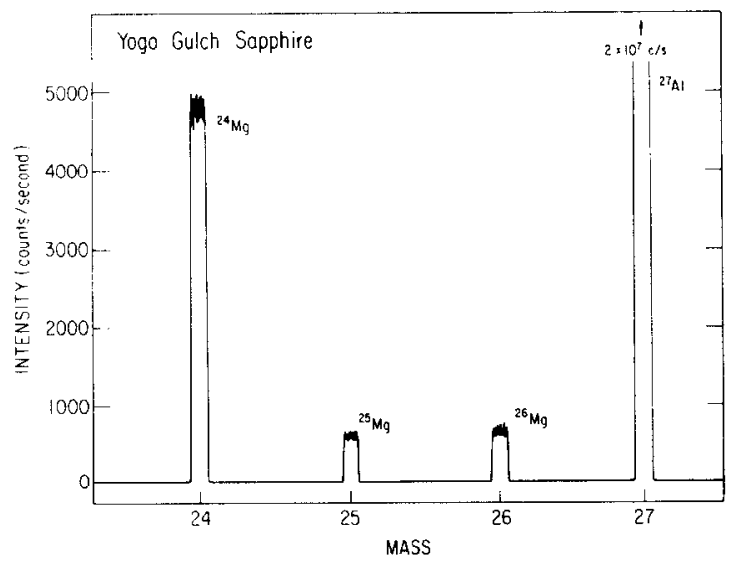

FIG. 1. Mass spectrum of Yogo Gulch sapphire. The constant, low level of the background and the absence of scattered ion peaks are evident. Total magnesium content of the sample is $113 \mathrm{ppm}$. amount of instrumental mass fractionation was very sensitive to the tuning of the secondary ion extraction system (Hutcheon, 1981). To optimize reproducible tuning, we followed the technique discussed by Hutcheon (1981) in which the system is tuned for maximum ${ }^{24} \mathrm{Mg}^{+}$intensity, flattopped peaks and uniform transmission over the mass range 48 to 20 . The isotopic data were corrected for fractionation using the measured slope of the fractionation line after normalizing observed ${ }^{25} \mathrm{Mg} /{ }^{24} \mathrm{Mg}$ ratios to the NBS standard value, 0.12663 (Catanzaro et al., 1966):

$$
\begin{aligned}
\left({ }^{26} \mathrm{Mg} /{ }^{24} \mathrm{Mg}\right)_{N}= & \left({ }^{26} \mathrm{Mg} /{ }^{24} \mathrm{Mg}\right)_{O B S} \\
& +\frac{1}{0.485}\left[0.12663-\left({ }^{26} \mathrm{Mg} /{ }^{24} \mathrm{Mg}\right)_{O B S}\right]
\end{aligned}
$$

This fractionation correction removes the effect of massdependent fractionation both in the ion probe and in nature and the corrected ${ }^{26} \mathrm{Mg} /{ }^{24} \mathrm{Mg}$ ratios reflect only non-massdependent isotopic effects. With this fractionation correction, the terrestrial $\mathrm{Mg}$ isotopic data define a "normal" ${ }^{26} \mathrm{Mg} /{ }^{24} \mathrm{Mg}$ ratio of 0.13938 (Hutcheon, 1981) and variations in ${ }^{26} \mathrm{Mg} /{ }^{24} \mathrm{Mg}$ ratios were calculated as $\delta_{N}{ }^{26} \mathrm{Mg}$ in permil relative to this normal value:

$$
\delta_{N}{ }^{26} \mathrm{Mg}=\left[\frac{\left({ }^{26} \mathrm{Mg} /{ }^{24} \mathrm{Mg}\right)_{N}}{0.13938}-1\right] \times 1000 .
$$

The ${ }^{27} \mathrm{Al} /{ }^{24} \mathrm{Mg}$ ratio of each sample was calculated from the ${ }^{27} \mathrm{Al}^{+}$and ${ }^{24} \mathrm{Mg}^{+}$intensities measured, as discussed above, at the exact locations analyzed isotopically. The secondary ion intensity ratios were calibrated against electron probe measurements in hibonite. The calibration is linear over a range in ${ }^{27} \mathrm{Al} /{ }^{24} \mathrm{Mg}$ of 14 to 200 and the slope of the calibration line, 1.34 , reflects the higher yield of ${ }^{24} \mathrm{Mg}^{+}$ relative to ${ }^{27} \mathrm{Al}^{+}$. This calibration has remained constant during the 18 months we have analyzed hibonite, and is not affected by minor changes in instrument tuning. To correct the ${ }^{77} \mathrm{Al}^{+} /{ }^{24} \mathrm{Mg}^{+}$ratios measured in BB-5 corundum, we were forced to use the hibonite calibration since we were unable to find a terrestrial corundum or sapphire with sufficient $\mathrm{Mg}$ that it can be measured accurately with the electron probe. It is possible that the relative yields of ${ }^{27} \mathrm{Al}^{+}$ and ${ }^{24} \mathrm{Mg}^{+}$are different in corundum and hibonite but, since the slope of the $\mathrm{Al} / \mathrm{Mg}$ calibration line for plagioclase, 1.22 (Hutcheon, 1981), differs from that of the hibonite line by only $\sim 10 \%$, we feel that differences in matrix effects between hibonite and corundum are unlikely. Errors are calculated as two standard deviations of the mean from, typically, 20 measurements per analysis.

\section{RESULTS}

As seen in the SEM photo in Fig. 2, the inclusion is composed of three phases: corundum $(23 \%$ by area), hibonite $(77 \%)$ and perovskite (trace). The corundum appears in Fig. 2 as two compact masses, with hibonite surrounding one completely and enclosing the other partially. Subsequent re-polishing of the sample has shown, however, that these two areas merge into one in the third dimension. Hibonite may have surrounded the entire mass completely prior to splitting of the inclusion during sample preparation. Optically, the corundum is invisible and shows no birefringence, the latter suggesting that its optic axis is perpendicular to the plane of the thin section. It is so colorless and transparent that only the pleochroism and birefringence of hibonite crystals below the corundum can be seen. The fact that the corundum is largely, if not completely, sur- 


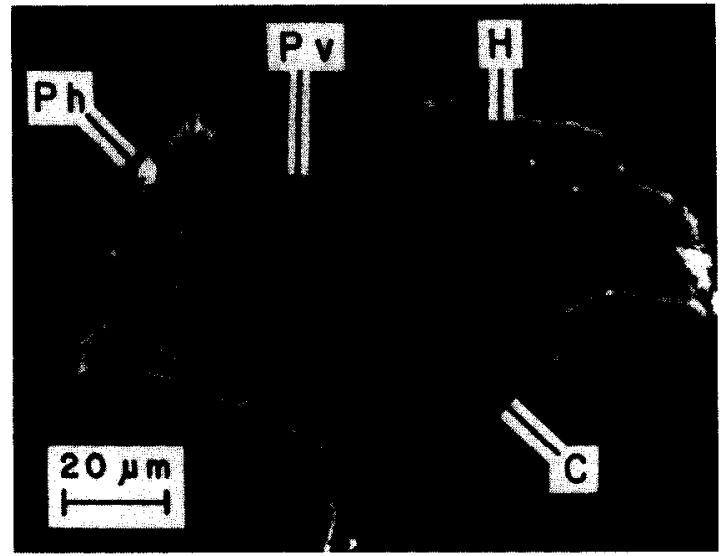

FIG. 2. SEM photomicrograph of BB-5 obtained by backscattered electron imaging. Hibonite $(\mathrm{H})$ mantling and, in places, enclosing corundum (C). Perovskite $(P v$, white streaks) forms elongated crystals between hibonite blades. Some iron-rich phyllosilicate material ( $\mathrm{Ph}$, white amorphous blobs) adheres to inclusion surface. Dark grey area at lower right is not corundum, but a shadowing effect.

rounded by hibonite suggests that corundum formed before hibonite. The corundum has sharp, straight contacts with hibonite in some places but very irregular contacts in others, as if the corundum were originally a euhedral crystal which was later partially corroded in a reaction to form hibonite. Optical studies show that the hibonite is blue, pleochroic and polycrystalline. Individual crystals are elongate blades, $30-70 \mu \mathrm{m}$ by $10-20 \mu \mathrm{m}$. Long axes of hibonite crystals are locally parallel to one another and to long axes of perovskite grains which reveal the directions of orientation in Fig. 2: to the left, the direction is vertical and at the top, horizontal, as if the hibonite crystals "wrap around" the corundum. The control of the orientation of hibonite crystals suggested by this relationship again implies that hibonite formed after corundum. Perovskite is absent from the corundum. White grains at the edge of BB5 are iron-rich phyllosilicates which are found in the matrix of this meteorite and are sometimes attached to the outsides of inclusions separated by the freezethaw technique. The positions of these grains thus define the outer surface of the inclusion and suggest that the spherule has a corundum core surrounded by a mantle of hibonite and perovskite.

Electron microprobe analyses of corundum and hibonite are shown in Table 1 . The corundum is virtually pure $\mathrm{Al}_{2} \mathrm{O}_{3}$. The hibonite is noteworthy for its low $\mathrm{MgO}$ and $\mathrm{TiO}_{2}$ contents relative to most other meteoritic hibonites (Keil and Fuchs, 1971; Allen et al., 1978; Macdougall, 1979). A phase whose composition is very close to pure $\mathrm{Al}_{2} \mathrm{O}_{3}$ was observed by Kurat (1970) in the C3 meteorite Lancé. The primary phase assemblage of that inclusion was described as being composed almost completely of spinel, with some $\mathrm{Al}_{2} \mathrm{O}_{3}$ crystals in the interior. Without a more detailed textural description, it is difficult to comment on its relation to BB-5.
All ion probe isotope data are presented in Table 2 where we show the measured ${ }^{25} \mathrm{Mg} /{ }^{24} \mathrm{Mg}$ and ${ }^{26} \mathrm{Mg} /{ }^{24} \mathrm{Mg}$ ratios, corrected only for the ${ }^{48} \mathrm{Ca}^{++}$interference, where appropriate. The normalized $\delta_{N}{ }^{26} \mathrm{Mg}$ values and the ${ }^{27} \mathrm{Al} /{ }^{24} \mathrm{Mg}$ ratios measured with the ion probe and corrected by the calibration factor of 1.34 are also shown. Errors in all cases are two standard deviations of the mean. Four terrestrial samples were analyzed concurrently with BB-5: Loire Valley spinel, Madagascar hibonite, Miyake anorthite and Yogo Gulch sapphire. At least one of these terrestrial samples was run prior to each BB-5 analysis and the data in Table 2 show that all terrestrial samples consistently yielded $\delta_{N}{ }^{26} \mathrm{Mg}=0$ within $2 \sigma_{\text {mean }}$, independent of the sample's $\mathrm{Al} / \mathrm{Mg}$ ratio or composition. Additional data from terrestrial sam-

\section{TABLE 1}

Electron microprobe analyses of phases in the corundum-hibonite spherule (weight per cent)

Corundum Hibonite

\begin{tabular}{|c|c|c|}
\hline $\mathrm{CaO}$ & 0.01 & 8.34 \\
\hline $\mathrm{TiO}_{2}$ & 0.32 & 2.01 \\
\hline $\mathrm{V}_{2} \mathrm{O}_{3}$ & n.d. & 0.03 \\
\hline FeO & n.d. & 0.03 \\
\hline $\mathrm{SiO}_{2}$ & 0.04 & 0.01 \\
\hline $\mathrm{MgO}$ & $\leq 0.02 *$ & 0.65 \\
\hline $\mathrm{Al}_{2} \mathrm{O}_{3}$ & 98.53 & 87.63 \\
\hline Total & 98.90 & $\underline{98.70}$ \\
\hline \multirow[t]{2}{*}{ Cations } & $s$ on the & basis of \\
\hline & $3(0)$ & $19(0)$ \\
\hline$\overline{\mathrm{Ca}}$ & 0.00 & 1.01 \\
\hline $\mathrm{Ti}$ & 0.00 & 0.17 \\
\hline V & -- & 0.00 \\
\hline $\mathrm{Fe}$ & -- & 0.00 \\
\hline $\mathrm{Si}$ & 0.00 & 0.00 \\
\hline $\mathrm{Mg}$ & -- & 0.11 \\
\hline A1 & 1.99 & 11.69 \\
\hline Total & 1.99 & 12.98 \\
\hline
\end{tabular}

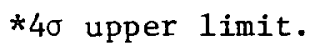

n.d. -- not detected. 
TABLE 2

Ion probe $\mathrm{Mg}$ isotope analyses

\begin{tabular}{|c|c|c|c|c|c|}
\hline & ${ }^{25} \mathrm{Mg} /{ }^{24} \mathrm{Mg}$ & ${ }^{26} \mathrm{Mg} /{ }^{24} \mathrm{Mg}$ & $\delta_{\mathrm{N}}{ }^{26} \mathrm{Mg}\left(\%_{0}\right)$ & $\delta_{\mathrm{N}}^{26} \mathrm{Mg}\left(\%_{0}\right)(\mathrm{b})$ & ${ }^{27} \mathrm{~A} 1 /{ }^{24} \mathrm{Mg}$ \\
\hline \multicolumn{6}{|l|}{ Terrestrial Samples } \\
\hline \multirow[t]{2}{*}{ Loire Valley Spinel } & $12600 \pm 12$ & $13793 \pm 13$ & $-1.1 \pm 2.0$ & & \\
\hline & $12693 \pm 12$ & $14007 \pm 12$ & $0.5 \pm 1.9$ & $-0.3 \pm 1.4$ & 2.5 \\
\hline \multirow[t]{2}{*}{ Madagascar Hibonite ${ }^{(a)}$} & $\begin{array}{l}12489 \pm 12 \\
12556 \pm 13 \\
12534 \pm 14 \\
12623 \pm 13\end{array}$ & $\begin{array}{l}13569 \pm 14 \\
13704 \pm 14 \\
13671 \pm 16 \\
13870 \pm 15\end{array}$ & $\begin{aligned}-0.7 & \pm 2.1 \\
-1.0 & \pm 2.2 \\
0 & \pm 2.3 \\
1.0 & \pm 2.2\end{aligned}$ & & \\
\hline & & & & $-0.2 \pm 1.4$ & $36 \pm 1$ \\
\hline \multirow[t]{2}{*}{ Miyake Anorthite ${ }^{(a)}$} & $\begin{array}{l}12628 \pm 22 \\
12594 \pm 24\end{array}$ & $\begin{array}{l}13859 \pm 28 \\
13802 \pm 25\end{array}$ & $\begin{array}{r}-0.5 \pm 3.3 \\
0.5 \pm 2.8\end{array}$ & & \\
\hline & & & & $0 \pm 2.2$ & $240 \pm 5$ \\
\hline \multirow[t]{2}{*}{ Yogo Gulch Sapphire } & $\begin{array}{l}12618 \pm 25 \\
12706 \pm 30\end{array}$ & $\begin{array}{l}13848 \pm 28 \\
14036 \pm 36\end{array}$ & $\begin{array}{l}0.1 \pm 4.0 \\
0.6 \pm 5.0\end{array}$ & & \\
\hline & & & & $0.3 \pm 3.0$ & $5272 \pm 123$ \\
\hline \multicolumn{6}{|l|}{ Murchison BB-5 } \\
\hline \multirow[t]{2}{*}{ Hibonite ${ }^{(a)}$} & $\begin{array}{l}12479 \pm 15 \\
12494 \pm 14 \\
12515 \pm 16\end{array}$ & $\begin{array}{l}13646 \pm 14 \\
13696 \pm 15 \\
13729 \pm 17\end{array}$ & $\begin{array}{l}6.3 \pm 2.3 \\
7.7 \pm 2.4 \\
6.9 \pm 2.6\end{array}$ & & \\
\hline & & & & $7.0 \pm 1.6$ & $130 \pm 15$ \\
\hline Corundum & $\begin{array}{l}12534 \pm 38 \\
12571 \pm 30\end{array}$ & $\begin{array}{l}13715 \pm 53 \\
13818 \pm 32\end{array}$ & $\begin{array}{l}3.1 \pm 6.6 \\
5.0 \pm 4.8\end{array}$ & & $\begin{array}{l}12750 \pm 2700 \\
27430 \pm 715\end{array}$ \\
\hline
\end{tabular}

ples discussed in Hutcheon (1981) also consistently show the same behavior, giving us confidence that $\delta_{N}{ }^{26} \mathrm{Mg}$ values differing from zero by more than $2 \sigma_{\text {mean }}$ reflect true variations in $\mathrm{Mg}$ isotopic composition beyond the range of any instrumental effects. Two analyses of Yogo Gulch sapphire, containing only $\sim 110 \mathrm{ppm}$ of $\mathrm{Mg}$, yielded $\delta_{N}{ }^{26} \mathrm{Mg}=0$, demonstrating the absence of any significant background in the presence of an intense ${ }^{27} \mathrm{Al}^{+}$signal and the absence of any systematic effects in the ion probe's ability to measure $\mathrm{Mg}$ isotope ratios at very low $\mathrm{Mg}$ concentrations. The grand mean values for $\left({ }^{26} \mathrm{Mg} /\right.$ $\left.{ }^{24} \mathrm{Mg}\right)_{N}$ ratios and the corresponding $\delta_{N}{ }^{26} \mathrm{Mg}$ for the terrestrial samples are plotted on the ${ }^{26} \mathrm{Al}-{ }^{26} \mathrm{Mg}$ isochron diagram, Fig. 3. It is clear that there are no deviations from $\delta_{N}{ }^{26} \mathrm{Mg}=0$ over a range in ${ }^{27} \mathrm{Al} /$ ${ }^{24} \mathrm{Mg}$ of $\sim 2000$.

The data from the terrestrial samples also define the range of instrumental mass fractionation experienced during these analyses. Data from hibonite exhibited consistently negative $\delta^{25} \mathrm{Mg}$ and $\delta^{26} \mathrm{Mg}$ values and fractionation was observed over the interval from -13.7 to $+2.4 \%$ /a.m.u. The amount of fractionation is very similar to that reported by Hutcheon
(1981) but the range is shifted toward the light isotopes by the hibonite analyses. Isotopic ratios from samples of undetermined isotopic composition falling within this fractionation range must be considered to reflect only instrumental and not natural effects.

Three areas of BB-5 hibonite were analyzed on three different days and both the $\mathrm{Mg}$ isotopic and $\mathrm{Al} / \mathrm{Mg}$ elemental ratios are consistent among all three runs. The grand mean value for the $\left({ }^{26} \mathrm{Mg} /\right.$ $\left.{ }^{24} \mathrm{Mg}\right)_{N}$ ratio shows a small but distinct ${ }^{26} \mathrm{Mg}$ excess, $\delta_{N}{ }^{26} \mathrm{Mg}=7.0 \pm 1.7 \%$, which is clearly resolved, even at the $4 \sigma$ level, from ${ }^{26} \mathrm{Mg} /{ }^{24} \mathrm{Mg}$ ratios of the terrestrial samples. The raw isotopic ratios from one of the BB-5 analyses lie slightly outside the range of fractionation observed for the terrestrial hibonite, but ratios from the other two analyses lie within the range and we attach no particular significance to the degree of fractionation in the first data set. The mean ${ }^{27} \mathrm{Al} /$ ${ }^{24} \mathrm{Mg}$ ratio obtained from the ion probe data, 130 \pm 15 , agrees well with the ${ }^{27} \mathrm{Al} /{ }^{24} \mathrm{Mg}$ ratio measured with the electron probe, 133. Since the corrected $\delta_{N}{ }^{26} \mathrm{Mg}$ values and ${ }^{27} \mathrm{Al} /{ }^{24} \mathrm{Mg}$ ratios for all three analyses overlap one another, only the grand mean values for $\left({ }^{26} \mathrm{Mg} /{ }^{24} \mathrm{Mg}\right)_{N}$ and ${ }^{27} \mathrm{Al} /{ }^{24} \mathrm{Mg}$ are plotted 


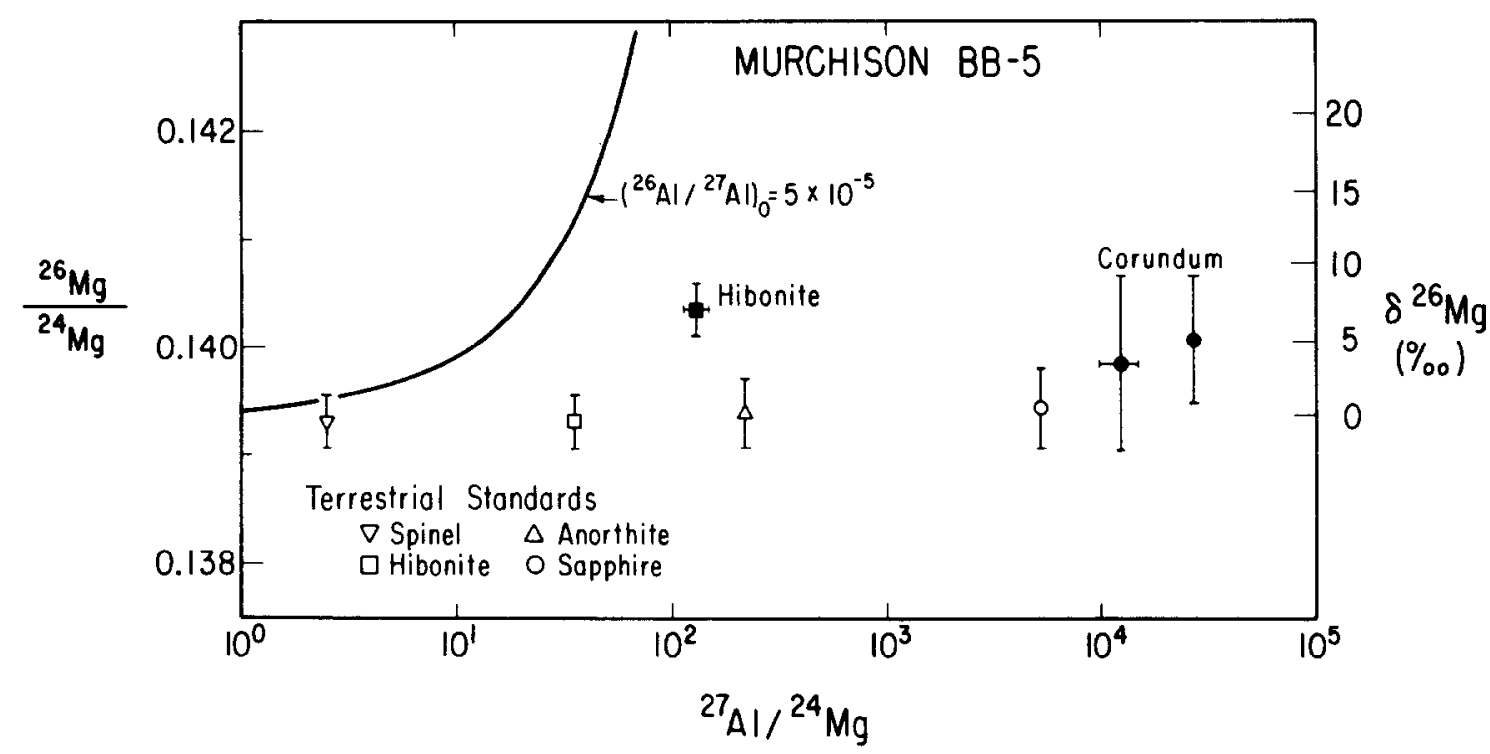

FIG. 3. Al-Mg evolution diagram for Murchison BB-5. The correlation line for BB-5 hibonite and corundum has essentially zero slope, suggesting a uniform enrichment in ${ }^{26} \mathrm{Mg}$ of $\sim 7 \%$. A correlation line through the terrestrial samples, which were analyzed concurrently, also has zero slope but a much lower intercept. A semilogarithmic plot is used rather than the conventional linear one to accommodate the extraordinary range in ${ }^{27} \mathrm{Al} /{ }^{24} \mathrm{Mg}$ ratios. On it, the standard Allende $\mathrm{Al}-\mathrm{Mg}$ isochron plots as a curve, rather than a straight line.

in Fig. 3. Two areas of BB-5 corundum were analyzed and, while the isotopic data from both runs are consistent, the ${ }^{27} \mathrm{Al} /{ }^{24} \mathrm{Mg}$ ratios from the two areas differ by about a factor of two. Higher precision was obtained in the second run, even though the second area contains less $\mathrm{Mg}$ than the first. This is due to greater stability of the secondary ion beam which is reflected in the standard deviations of both the isotopic and elemental ratios. The $\left({ }^{26} \mathrm{Mg} /{ }^{24} \mathrm{Mg}\right)_{N}$ ratio for the first area, $\delta_{N}{ }^{26} \mathrm{Mg}=3.1 \pm 6.5 \%$, lies within $1 \sigma$ of normal $\mathrm{Mg}$, while the $\left({ }^{26} \mathrm{Mg} /{ }^{24} \mathrm{Mg}\right)_{N}$ ratio for the second area, $\delta_{N}{ }^{26} \mathrm{Mg}=5.0 \pm 4.7 \%$, lies just outside of nor$\mathrm{mal} \mathrm{Mg}$ in the $2 \sigma$ limit. The raw isotopic ratios from both areas lie well within the range of fractionation observed for terrestrial samples and, together with the raw isotopic ratios for hibonite, provide no evidence for mass-fractionated $\mathrm{Mg}$ like that found in Allende FUN inclusions (Wasserburg et al., 1977) or in Murchison hibonite MH-8 (Macdougall and Phinney, 1979). Both of the corundum ${ }^{27} \mathrm{Al} /{ }^{24} \mathrm{Mg}$ ratios calculated from the ion probe data are consistent with the upper limit on $\mathrm{Mg}$ content $(\sim 200$ $\mathrm{ppm}$ ) established with the electron probe.

The polished section of BB-5 was examined with an SEM before and after the ion probe runs to verify that $\mathrm{Mg}$ detected in the corundum was not due to overlap of the primary beam onto relatively $\mathrm{Mg}$-rich hibonite. The ion probe burn holes from both corundum analyses were completely contained within corundum, but we cannot exclude the possibility that $\mathrm{Mg}$ is concentrated in sub-micron-sized hibonite crystals dispersed throughout the corundum. The
SEM study provided no insight into the variable $\mathrm{Mg}$ content detected in the ion probe analyses.

\section{DISCUSSION}

The small ${ }^{26} \mathrm{Mg}$ effect in BB-5 contrasts strongly with the expectation of a large ${ }^{26} \mathrm{Mg}$ excess in a presumed very early condensate with such a high ${ }^{27} \mathrm{Al} /$ ${ }^{24} \mathrm{Mg}$ ratio. The $\left({ }^{26} \mathrm{Mg} /{ }^{24} \mathrm{Mg}\right)_{N}$ value for corundum overlaps normal $\mathrm{Mg}$ at the $2 \sigma$ limit, but even the upper $2 \sigma$ limit to the ${ }^{26} \mathrm{Mg}$ enrichment, $\delta_{N}{ }^{26} \mathrm{Mg}=$ $10 \%$, is remarkably small considering the very refractory composition of BB- 5 and the extremely high ${ }^{27} \mathrm{Al} /{ }^{24} \mathrm{Mg}$ ratios, up to 27,400 . Because of the exceedingly high ${ }^{27} \mathrm{Al} /{ }^{24} \mathrm{Mg}$ value of $\mathrm{BB}-5$ corundum, an $\mathrm{Al}-\mathrm{Mg}$ model isochron extending from normal $\mathrm{Mg}$ composition, $\delta_{N}{ }^{26} \mathrm{Mg}=0$ at ${ }^{27} \mathrm{Al} /{ }^{24} \mathrm{Mg}=0$ through the BB-5 hibonite point on Fig. $3\left(\delta_{N}{ }^{26} \mathrm{Mg}=7,{ }^{27} \mathrm{Al} /\right.$ ${ }^{24} \mathrm{Mg}=130$ ) would predict that nearly $25 \%$ of the total $\mathrm{Mg}$ in $\mathrm{BB}-5$ corundum would be ${ }^{26} \mathrm{Mg}$, giving $\delta_{N}{ }^{26} \mathrm{Mg} \sim 1470 \%$, corresponding to a ${ }^{26} \mathrm{Mg}$ excess nearly 300 times that observed. The data from BB5 clearly do not define the type of linear correlation between ${ }^{26} \mathrm{Mg} /{ }^{24} \mathrm{Mg}$ and ${ }^{27} \mathrm{Al} /{ }^{24} \mathrm{Mg}$ ratios common to many Allende refractory inclusions (Lee, 1979; Hutcheon, 1981), as no straight-line isochron can be constructed which passes through normal $\mathrm{Mg}$ and the BB-5 data. The canonical Allende Al- $\mathrm{Mg}$ isochron with slope $\left({ }^{26} \mathrm{Al} /{ }^{27} \mathrm{Al}\right)_{0} \sim 5 \times 10^{-5}$ becomes a curve on the semi-logarithmic scale of Fig. 3 and all of the BB-5 data lie far below this isochron. The only correlation lines defined by the BB- 5 data are a series of nearly horizontal lines whose slopes differ 
from zero by less than 3 parts in $10^{8}$ with intercepts corresponding to ${ }^{26} \mathrm{Mg} /{ }^{24} \mathrm{Mg}$ ratios between 0.14170 and 0.13960 .

Due to the size of the errors on the isotopic composition of BB-5 corundum, the data do not define a unique $\mathrm{Mg}$ isotopic composition for $\mathrm{BB}-5$ as a whole. The strongest statement supported by the isotopic data is that the ${ }^{26} \mathrm{Mg} /{ }^{24} \mathrm{Mg}$ ratio measured in BB-5 corundum is higher than that measured in any of the terrestrial samples analyzed in this study or by Hutcheon (1981). In our view, the combination of isotopic data and petrographic evidence for a reaction relationship between corundum and hibonite strongly suggest, but do not prove, that the two phases have identical $\mathrm{Mg}$ isotopic compositions such that BB-5, as a whole, is isotopically homogeneous. This assumption forms the basis for much of the following discussion.

If $\mathrm{BB}-5$ is isotopically heterogeneous, two classes of models arise. In the first, corundum and hibonite initially had the same isotopic composition but subsequent exchange with a reservoir of different isotopic composition affected one phase more than the other. This scenario seems unlikely because of the intimate contact between the two phases and the small size of the inclusion. In the second class of models, corundum and hibonite formed in separate reservoirs with different $\mathrm{Mg}$ isotopic compositions. This would be possible if formation of hibonite were rapid enough that $\mathrm{Mg}$ was unable to diffuse across the corundum-hibonite contact to any appreciable degree. This model is viable, but is not pursued further here.

The texture of BB- 5 shows that corundum formed before hibonite and suggests that the latter formed by reaction of the former. It is difficult to tell from textures, however, whether BB-5 is a direct vapor-tosolid condensate or a product of crystallization from a melt, although interpretation of the $\mathrm{Mg}$ isotopic data in terms of internal heterogeneity would preclude melting after the heterogeneity was established. First, we explore the possibility that the inclusion crystallized from a melt and then that it is a direct solid condensate from the solar nebula.

\section{Liquid Origin}

If BB-5 crystallized from a melt, the inclusion's major element composition poses important constraints on origin. From its modal mineralogy and the chemical analyses and densities of its phases, the bulk composition of $\mathrm{BB}-5$ is $91.5 \% \mathrm{Al}_{2} \mathrm{O}_{3}, 6.4 \% \mathrm{CaO}$, $1.6 \% \mathrm{TiO}_{2}$ and $0.5 \% \mathrm{MgO}$. It is impossible to produce a liquid of this composition by normal magmatic differentiation processes on planets whose $\mathrm{Al} / \mathrm{Si}$ ratio is anywhere near the solar ratio. The material that was melted must have been very $\mathrm{Al}_{2} \mathrm{O}_{3}$-rich and $\mathrm{SiO}_{2}-$ $\mathrm{MgO}$-poor and could have been produced only in a very high temperature vapor-condensed phase fractionation process like that discussed below. Accord- ing to the one atmosphere liquid-crystal phase diagram for the system $\mathrm{Al}_{2} \mathrm{O}_{3}-\mathrm{CaO}$ (Morey, 1964), the temperature range required for melting material of the composition of $\mathrm{BB}-5$ is $2120-2220^{\circ} \mathrm{K}$. If it is assumed that this inclusion, like all other meteoritic materials, did not form deep within a planet, the origin of such extreme temperatures is a fundamental problem. In fact, the difficulty in finding the mechanisms for production of these temperatures is the major obstacle to a liquid origin model for BB-5.

Equilibrium condensation of liquids will yield refractory condensates with compositions similar to that of BB-5 (Blander and Fuchs, 1975), but the temperature and pressure ( $10^{2}$ atm.) needed to condense such materials at equilibrium are far higher than the temperatures and pressures thought to have existed in the primitive solar nebula (Cameron and Pine, 1973). A possibility worth considering, however, is that, under conditions normally considered for the nebula, BB-5 might have condensed as a metastable liquid, subcooled relative to its liquidus, as suggested by Blander and Katz (1967) as a general mechanism for production of all meteoritic chondrules. The problem with this model is that nucleation occurs very quickly in $\mathrm{SiO}_{2}$-free oxide melts at temperatures below their liquidi. Evidence for this may be seen in experiments by Keil et al. (1973) in which a laser beam was used to melt droplets from the end of a spinning $\mathrm{Al}_{2} \mathrm{O}_{3}$ rod. This technique was successful in subcooling the free-falling droplets so produced by about $450^{\circ} \mathrm{K}$; yet, despite very high cooling rates, $800^{\circ} \mathrm{K}-\mathrm{sec}^{-1}$, these melts were only able to persist metastably for $<0.6 \mathrm{sec}$ and could not be quenched to glass. Apparently, diffusion and formation of critical nuclei are so rapid in such melts that crystallization begins within one second after cooling below the liquidus. Because solar nebular cooling rates are believed to be many orders of magnitude lower than those of these experiments, such a droplet, if it could have formed in the nebula, would have subcooled much less than $450^{\circ} \mathrm{K}$. Therefore, because the liquidus temperature of BB-5 is $2220^{\circ} \mathrm{K}$, a liquid of that composition could not have persisted in the nebula, even metastably, below at least $1770^{\circ} \mathrm{K}$ without crystallizing, according to these experiments. Blander and Fuchs (1975) estimated that a liquid having a very similar bulk composition to that of $\mathrm{BB}$ 5 would condense metastably a few tens of degrees below the equilibrium condensation temperature of solid hibonite. Taking $1742^{\circ} \mathrm{K}$, the condensation temperature of corundum at $10^{-3}$ atm. pressure (Lattimer and Grossman, 1978), as an upper limit to the condensation temperature of hibonite, we conclude that Blander and Fuchs' assertion requires persistence of such a melt to $1720^{\circ} \mathrm{K}$ at most, at least $50^{\circ}$ lower than seems possible from the above consideration of the maximum subcooling to be expected for such compositions. Further evidence that BB-5 did not condense as a metastable liquid comes from textures. In experiments like those of Keil et al. 
(1973), Nelson et al. (1972) showed that $\mathrm{Al}_{2} \mathrm{O}_{3}$ droplets solidify with spherulitic textures as a result of being subcooled by amounts comparable to those in the work of Keil et al. (1973). We have seen that at least this degree of subcooling would have been required for BB-5 to condense as a metastable liquid instead of corundum and hibonite, but no textures even remotely resembling those of Nelson et al. (1972) are present in BB-5. We conclude from both theoretical and textural arguments that formation of BB-5 as a metastable liquid condensate is highly improbable.

In a model for the origin of chondrites, Cameron (1979) suggested that a large number of giant gaseous protoplanets developed in the solar nebula. The interiors of such objects were so hot that clumps of solids sinking inwards would have either melted to form droplets or would have vaporized. After escaping from the protoplanet, the products of quenching of the droplets and condensation of the gas would have accumulated to form asteroids. The mechanism for escape of condensed materials from the gravity field of a protoplanet is entrainment during tidal stripping of the gaseous envelope from the liquid core. Although temperatures predicted for such protoplanetary interiors are certainly high enough to melt solids having the composition of BB-5, there are still important unsolved problems with this class of model. First, difficulties are encountered in releasing both chondrules and materials which condensed directly as solids from the same protoplanet, even though both types of objects are found in each carbonaceous chondrite. Second, since the relative abundances of the non-volatile elements in the chondrites are the same as those in the sun, it is highly unlikely that the materials which accumulated to form them were made in these processes which have such great potential for fractionating the elements from one another and for keeping them separated. For these reasons, we consider this to be a very improbable model for the origin of chondritic material in general and BB-5 in particular.

Hypervelocity collisions between grains in the nebula (Kieffer, 1975) and impacts between projectiles and asteroidal targets (Kieffer and Simonds, 1980) may have occurred occasionally with velocities high enough to achieve temperatures sufficient to melt materials of this composition. Production of such materials as liquid volatilization residues or liquid condensates from vapor made in impact events, however, is considered unlikely because no objects of this composition have ever heen ohserved in lunar samples and impact velocities are usually higher on the moon than on the asteroids.

Thus, if BB-5 formed from a melt, the only model compatible with the required high temperatures seems to be collisions between grains of high-temperature condensates or impact on parent bodies made of refractory condensates. The uniform enrichment in ${ }^{26} \mathrm{Mg}$, independent of ${ }^{27} \mathrm{Al} /{ }^{24} \mathrm{Mg}$ ratio, in BB-5 is compatible with such a model, providing that almost all of the ${ }^{26} \mathrm{Al}$ decayed prior to the melting event. The only previous case of uniform enrichment, Allende inclusion B-30, was also attributed to closed-system re-equilibration via melting (Lee et al., 1976). In the case of BB-5, if the precursor began with normal $\mathrm{Mg}$ and melting was isochemical, BB5 's bulk ${ }^{27} \mathrm{Al} /{ }^{24} \mathrm{Mg}$ ratio, 184 , and $\delta_{N}{ }^{26} \mathrm{Mg}, 7 \%$, imply that the precursor had an initial ${ }^{26} \mathrm{Al} /{ }^{27} \mathrm{Al}$ ratio of $5.4 \times 10^{-6}$. If the solar system was homogeneous in $\mathrm{Al}$ isotopic composition, then the small, but clearly resolved, ${ }^{26} \mathrm{Mg}$ excess in BB-5 places the time of initial formation of the precursor $\sim 2.2$ million years after the formation of Allende Type $B$ inclusions whose initial ${ }^{26} \mathrm{Al} /{ }^{27} \mathrm{Al}$ ratios were $5 \times 10^{-5}$ (Lee et al., 1976). The maximum slope of an isochron allowed by the data for BB- 5 hibonite and corundum corresponds to $\left({ }^{26} \mathrm{Al} /{ }^{27} \mathrm{Al}\right)_{0}<2 \times 10^{-8}$. In order for the precursor's ${ }^{26} \mathrm{Al} /{ }^{27} \mathrm{Al}$ ratio to evolve to this level from its initial value of $5.4 \times 10^{-6}, 6.1$ million ycars had to elapse between formation of the precursor and the melting event which produced BB-5. Although it seems unlikely that primitive condensate grains would still be colliding with one another so long after condensation was over, this time-scale is consistent with a model in which BB- 5 crystallized from a melt produced after repeated impact on a parent body of refractory composition. Alternatively, if the nebula was spatially heterogeneous in its ${ }^{26} \mathrm{Al} /{ }^{27} \mathrm{Al}$ ratio (Lee, 1979; Hutcheon, 1981), the precursor could have formed from a reservoir which had an initial ${ }^{26} \mathrm{Al} /{ }^{27} \mathrm{Al}$ ratio of $5.4 \times 10^{-6}$. In this case, there is no necessary age difference between the precursor and Allende inclusions, but an origin by melting of condensate grains in the nebula is still improbable because of the 6.1 million year elapsed time between precursor formation and melting.

\section{Solid Condensate Origin}

The most recent equilibrium calculations of the sequence of condensation of minerals from a cooling gas of solar composition (Lattimer and Grossman, 1978) predict that, at $10^{-3}$ atm. total pressure, corundum condenses first at $1743^{\circ} \mathrm{K}$ followed by perovskite at $1677^{\circ} \mathrm{K}$. Corundum begins to react with gaseous $\mathrm{Ca}, \mathrm{Mg}$ and $\mathrm{Si}$ to form melilite $\left(\mathrm{Ca}_{2} \mathrm{Al}_{2} \mathrm{SiO}_{7}\right.$ $\mathrm{Ca}_{2} \mathrm{MgSi}_{2} \mathrm{O}_{7}$ ) at $1625^{\circ} \mathrm{K}$ and the corundum remaining after all the $\mathrm{Ca}$ is condensed reacts with gaseous $\mathrm{Mg}$ to form spinel $\left(\mathrm{MgAl}_{2} \mathrm{O}_{4}\right)$ at $1533^{\circ} \mathrm{K}$. Finally, melilite is predicted to react completely with the gas to form diopside, $\mathrm{CaMgSi}_{2} \mathrm{O}_{6}$, at $1438^{\circ} \mathrm{K}$. Type $\mathrm{A}$ inclusions (Grossman, 1975) in C3's like Allende have a primary phase assemblage consisting almost entirely of hibonite, perovskite, melilite and spinel. Of the large number of such inclusions so far studied, none contain corundum. Nevertheless, based on the presence of the other predicted condensates (Larimer and Anders, 1970; Marvin et al., 1970; Grossman, 1972) and chemical compositions of these inclusions 
(Grossman, 1980), most workers believe that Type $A$ inclusions are aggregates of phases that condensed from the hot gas of the solar nebula. Two explanations have been advanced for the presence of hibonite in and absence of corundum from these inclusions. First, hibonite could have condensed before corundum (Grossman, 1972; Blander and Fuchs, 1975). Second, corundum could have condensed first and later reacted with the gas at a lower temperature to form hibonite (Blander and Fuchs, 1975). Although the latter authors attempted to estimate the free energy of formation of hibonite, lack of precise thermodynamic data for this phase prevents confirmation of either suspicion.

If we assume that BB-5 condensed directly as a solid from the solar nebula and that it did so at equilibrium, important constraints can be placed on the condensation process. First, from the textures, corundum must have reacted with the gas to form hibonite, one of the suggestions of Blander and Fuchs (1975). Thus, the fact that hibonite is a condensate does not invalidate the prediction of Grossman (1972) that corundum is the highest-temperature phase into which a large fraction of any major element condensed. Lattimer and Grossman (1978) ignored hibonite as a possible condensate phase because of the lack of good thermodynamic data for it. Their condensation sequences show, however, that corundum consumes virtually all of the gaseous aluminum before reacting to form melilite. We conclude from BB-5 that hibonite becomes more stable than corundum before melilite forms and we can therefore assume that aluminum was completely condensed prior to the appearance of melilite in this instance as well. Although the amount of calcium in a gas of solar composition is nine times more than that required to store all of the aluminum in hibonite, it is impossible without thermodynamic data for that phase to tell if the reaction that converts corundum into hibonite was complete prior to formation of lower-temperature aluminous phases. Since corundum is still the first condensate and hibonite and perovskite are the only other phases present in BB5 , the assumption that this inclusion is an equilibrium condensate leads to the conclusion that all three phases condensed at higher temperatures than any other aluminous phases. Presumably, BB-5 stopped reacting with the nebular gas before it cooled to the point where lower-temperature condensates such as melilite, spinel and diopside could form. BB-5 is thus the most refractory major phase assemblage known.

It has been assumed throughout this section that BB-5 condensed from a gas of solar composition. One interpretation of the rarity of corundum-bearing inclusions, however, is that they condensed from a special reservoir of non-solar composition which was sampled only occasionally by carbonaceous chondrite parent bodies. According to this interpretation, the most abundant inclusion types condensed from a gas of solar composition in which hibonite, rather than corundum, may be the first condensate. The above discussion of the bearing of the existence of BB-5 on the general problem of condensation from a gas of solar composition should thus be considered with this caveat in mind.

If $\mathrm{BB}-5$ is interpreted as a direct vapor-solid condensate which did not melt since it formed, a uniform enrichment in ${ }^{26} \mathrm{Mg}$ in hibonite and corundum, spanning a range in ${ }^{27} \mathrm{Al} /{ }^{24} \mathrm{Mg}$ of 130 to 27,400 , is consistent with only two types of models. In the first, BB-5 initially contained abundant ${ }^{26} \mathrm{Al}$ but lost most of its radiogenic ${ }^{26} \mathrm{Mg}$ through exchange with a reservoir of normal $\mathrm{Mg}$ isotopic composition, presumably the nebular gas. For example, if BB-5 condensed from a reservoir having an ${ }^{26} \mathrm{Al} /{ }^{27} \mathrm{Al}$ ratio of 5 $\times 10^{-5}$, the corundum would contain $\sim 26 \mathrm{ppm}$ of radiogenic ${ }^{26} \mathrm{Mg}$. Since the corundum now contains $<40 \mathrm{ppm}$ total $\mathrm{Mg}$, the loss of $99.9 \%$ of the radiogenic ${ }^{26} \mathrm{Mg}$ would be required to produce the observed $\mathrm{Mg}$ isotopic composition. Because there is so little total $\mathrm{Mg}$ in the corundum, simple addition of normal $\mathrm{Mg}$ to it cannot produce the observed $\mathrm{Mg}$ isotopic composition without exceeding the observed $\mathrm{Mg}$ content by a very large amount, unless the corundum originally condensed with ${ }^{26} \mathrm{Al} /{ }^{27} \mathrm{Al} \leqslant 8 \times 10^{-8}$. This class of models is considered unlikely since there is no textural evidence such as the presence of secondary phases or recrystallization of original phases that would be expected in any such two-stage model.

In the second class of models, BB- 5 condenses from a reservoir containing $7 \%$ excess ${ }^{26} \mathrm{Mg}$ but very little ${ }^{26} \mathrm{Al}$. "Normal" $\mathrm{Mg}$ from this reservoir has ${ }^{26} \mathrm{Mg}$ / ${ }^{24} \mathrm{Mg}=0.14036$. An Al-Mg isochron connecting this intercept with the BB-5 data has a maximum slope corresponding to $\left({ }^{26} \mathrm{Al} /{ }^{27} \mathrm{Al}\right)_{0} \sim 1.5 \times 10^{-8}$. This ratio is the upper limit to the ${ }^{26} \mathrm{Al}$ content of the reservoir when BB-5 condensed. The reservoir could have been enriched in ${ }^{26} \mathrm{Mg}$ due to prior decay of ${ }^{26} \mathrm{Al}$ or due to nebular heterogeneity in the ${ }^{26} \mathrm{Mg}$ / ${ }^{24} \mathrm{Mg}$ ratio. If prior decay of ${ }^{26} \mathrm{Al}$ was responsible, a whole family of models can be constructed for the production of a reservoir with suitable isotopic characteristics, but none of these possibilities seems very likely. If, for example, the reservoir began with a normal $\mathrm{Mg}$ isotopic composition and a chondritic ${ }^{27} \mathrm{Al} /{ }^{24} \mathrm{Mg}$ ratio, an initial ${ }^{26} \mathrm{Al} /{ }^{27} \mathrm{Al}$ ratio of at least $10^{-2}$ would be required to produce a $7 \%$ excess of ${ }^{26} \mathrm{Mg}$. Such a high ${ }^{26} \mathrm{Al} /{ }^{27} \mathrm{Al}$ ratio is substantially greater than standard astrophysical calculations of the production ratio (Arnett and Wefel, 1978) which generally yield ${ }^{26} \mathrm{Al} /{ }^{27} \mathrm{Al} \sim 1-2 \times 10^{-3}$. Furthermore, the $10 \%$ upper limit on the ${ }^{26} \mathrm{Mg}$ excess in corundum, corresponding to ${ }^{26} \mathrm{Al} /{ }^{27} \mathrm{Al}<1.5 \times 10^{-8}$, requires that BB-5 would have had to condense at least $\mathbf{1 4}$ million years after the formation of such a reservoir. If the ${ }^{27} \mathrm{Al} /{ }^{24} \mathrm{Mg}$ ratio is allowed to exceed the chondritic value, both the initial ${ }^{26} \mathrm{Al} /{ }^{27} \mathrm{Al}$ ratio of the reservoir and the time required for decay of this ratio to a value of $1.5 \times 10^{-8}$ can be reduced. Taking a liberal upper limit for the ${ }^{27} \mathrm{Al} /{ }^{24} \mathrm{Mg}$ ratio 
of one thousand times the chondritic value gives an initial ${ }^{26} \mathrm{Al} /{ }^{27} \mathrm{Al}$ ratio of $\sim 1 \times 10^{-5}$, but only reduces the decay time to 6.7 million years. This time scale would require condensation of BB-5 several million years after the formation of typical Allende inclusions and it is difficult to imagine how high-temperature condensation events could have occurred over such a protracted period.

The extreme difficulty in producing a reservoir enriched in ${ }^{26} \mathrm{Mg}$ due to decay of ${ }^{26} \mathrm{Al}$ suggests that the ${ }^{26} \mathrm{Mg}$ excess of the reservoir reflects spatial nonuniformity in the distribution of ${ }^{26} \mathrm{Mg}$. This non-radiogenic ${ }^{26} \mathrm{Mg}$ excess requires that the $\mathrm{Mg}$ isotopic composition of the nebula was spatially heterogeneous due to incomplete mixing of different nucleosynthetic components with different ${ }^{26} \mathrm{Mg} /{ }^{24} \mathrm{Mg}$ ratios. Magnesium thus joins the list of stahle nuclides which were heterogeneously distributed in the nebula. In this model, BB-5 is the first sample containing excess ${ }^{36} \mathrm{Mg}$ not produced by decay of ${ }^{26} \mathrm{Al}$. Depletions in ${ }^{26} \mathrm{Mg}$ observed in several Allende Type B inclusions (Wasserburg et al., 1977; Esat et al., 1980) may be further evidence of $\mathrm{Mg}$ isotopic heterogeneity. If BB-5 is a direct gas-solid condensate, the non-radiogenic ${ }^{26} \mathrm{Mg}$ excess requires a reservoir containing a previously unobserved nucleosynthetic component. The chemical composition of this reservoir is unknown, but quite possibly was different from solar composition. If so, this difference would lend support to the possibility mentioned above that condensation of corundum did not occur in a gas of solar composition, but rather in a reservoir of exceptional composition

\section{Implications of $B B-5$ for the Condensation Sequence}

Hibonite is a common constituent of three kinds of refractory inclusions in carbonaceous chondrites. In Murchison and other C2 chondrites, the so-called blue spherules (MacPherson et al., 1980) and spinelhibonite inclusions (Macdougall, 1979) are composed almost entirely of hibonite, spinel and perovskite. Melilite is either completely absent (Fuchs et al., 1973) or is present only as a very minor phase. The other kind is the Type $\mathrm{A}$ inclusions which contain abundant melilite and spinel and minor hibonite and perovskite and which are found both in $C 2$ and $C 3$ chondrites. The earlier assumption that BB- 5 is an equilibrium solid condensate from a gas of solar composition led to the conclusion that hibonite and perovskite are higher-temperature condensates than the other constituents of these three kinds of inclusions. Because of the great abundance of hibonite compared to lower-temperature condensates in the blue spherules and hibonite-spinel inclusions and the relatively low abundance of hibonite compared to those phases in the Type $\mathrm{A}$ inclusions, the blue spherules and spinel-hibonite inclusions must be higher-temperature condensates than the Type $A$ inclusions.
As mentioned earlier, if BB-5 is an equilibrium solid condensate from a gas of solar composition, it is the highest temperature major phase assemblage observed so far. If the above deductions are correct, the next most refractory types would be the blue spherules and spinel-hibonite inclusions. According to this interpretation, corundum is absent from these inclusions because they equilibrated with the gas at a temperature below that at which corundum was completely converted to hibonite. Next would come the Type A inclusions, composed of abundant melilite and spinel and minor hibonite and perovskite. These inclusions equilibrated with the gas at a low enough temperature that not only had corundum reacted away to form hibonite, but also the hibonite had almost completely reacted to form spinel and melilite Finally, the $\mathrm{Ca}-$, Al-rich inclusions with the lowest equilibration temperatures would be the Allende Type B inclusions. These are composed of fassaite, spinel, melilite and anorthite. Although many of these may have been melted after condensation (MacPherson and Grossman, 1981), their bulk chemical compositions (Beckett et al., 1980) indicate that their precursors probably contained a large amount of diopside, a phase that is predicted to form when melilite reacts totally with the solar nebular gas. Thus, if this sequence is correct, most of the refractory inclusions in Murchison have higher equilibration temperatures than those in Allende. This suggestion was first made by Grossman et al. (1977), based on the fact that inclusions in Allende contain much melilite and little hibonite (Grossman, 1975) while the reverse is true in Murchison (Fuchs et al., 1973). Further evidence of higher condensation temperatures comes from trace element data (Boynton et al., 1980; Tanaka et al., 1980). Despite the range of condensation temperatures represented by these different inclusion types, they can still be described as refractory because they all equilibrated above the temperature at which the bulk of the condensable matter of the solar system began to condense in the form of magnesium silicates and metallic iron.

The sequence of equilibration temperatures inferred for the different types of refractory inclusions suffers from one major problem. The inference that blue spherules and spinel-hibonite inclusions have higher equilibration temperatures than Type $\mathrm{A}$ inclusions implies that spinel condensed before melilite, as the former inclusion types contain abundant spinel and little or no melilite, while the latter contain abundant spinel and melilite. This is inconsistent with the calculated condensation sequence, according to which the gas reacts with corundum to form melilite first and with the remaining corundum to form spinel later. Thus, if the sequence of reaction remains unchanged when hibonite reacts instead of corundum, it should be possible to produce inclusions composed of hibonite, perovskite and melilite, with no spinel, by isolation of condensates from the gas above a certain temperature, but impossible to produce the as- 
semblage hibonite, spinel, perovskite, with no melilite, in this way. Since the latter assemblage is the one observed in the blue spherules and spinel-hibonite inclusions, the inference that these condensed before the Type A's leads to the conclusion that spinel condensed before melilite. There is also evidence from the Type A inclusions themselves that spinel condensed before melilite. Grossman (1980) concluded that the fluffy Type A's condensed directly as solids from the solar nebular gas. In these inclusions, spinel is poikilitically enclosed by melilite, indicating that the sequence of crystallization is spinel first, then melilite. One possible explanation for these observations is that the sequence of formation of melilite and spinel may be inverted when hibonite, rather than corundum, reacts with the gas. In order to pursue this, we have performed some calculations using data from the computer programs employed by Lattimer and Grossman (1978). These show conclusively, even without thermodynamic data for hibonite, that, if a phase with the characteristics of hibonite, namely high aluminum content, relatively low calcium content and grcater stability than corundum, reacts with the gas instead of corundum, melilite will still form before spinel. As yet, there is no good explanation for this lack of consistency with the calculated condensation sequence. It is possible that kinetic factors or maybe even errors in thermodynamic data could be responsible.

There is an apparent contradiction between our contention that corundum is to be expected as an equilibrium condensate from a gas of solar composition and its complete absence from almost every high-temperature condensate inclusion which has been described. The explanation that would follow from the above discussion is that corundum is the first condensate of any of the major elements, but, for some unknown reason, equilibration of condensates with the gas was arrested in almost every case at temperatures below that at which corundum had reacted to form lower temperature minerals. Clayton (1979) argued that even the temperatures implied by these lower temperature assemblages are higher than was possible in the solar nebula and suggested that refractory inclusions condensed instead from hot supernova ejecta. Although this idea is far from widely accepted by cosmochemists, the problem of achieving high nebular temperatures is obviously exacerbated by BB-5 and it would take detailed isotopic studies of many elements in it to rule out such an origin for it conclusively.

\section{CONCLUSION}

The inclusion BB-5 is composed of corundum, hibonite and perovskite. Ion microprobe data show that corundum and hibonite probably have the same $\mathrm{Mg}$ isotopic composition, $\delta_{N}{ }^{26} \mathrm{Mg}=7 \%$, despite an enormous difference in their ${ }^{27} \mathrm{Al} /{ }^{24} \mathrm{Mg}$ ratios. Because of the extreme temperature required to melt an object with such a highly aluminous bulk chemical composition, a liquid origin is unlikely for BB-5, except possibly by hypervelocity collisions between nebular high-temperature condensate grains or impacts on parent bodies made from such refractory materials. Consideration of the time-scale implied by the isotopic data seems to rule out the former. If, instead, BB-5 is a direct gas-solid condensate from a gas of solar composition, it would be the highest-temperature major phase assemblage known. In this model, the uniform enrichment in ${ }^{26} \mathrm{Mg}$ must be a characteristic of the reservoir from which BB-5 condensed, as petrographic and isotopic data suggest that it is unlikely that a later process occurred in which the inclusion's $\mathrm{Mg}$ isotopic composition was modified by exchange or addition. Because severe difficulties are encountered in making such a reservoir by prior decay of ${ }^{26} \mathrm{Al}$, nebular heterogeneity in $\mathrm{Mg}$ isotopic composition is a preferred explanation.

Acknowledgments - We thank E. Olsen for meteorite specimens, T. Tanaka for mineral separations and R. N. Clayton, A. M. Davis, J. R. Goldsmith, W. D. Arnett, I. M. Steele, I. Kawabe and C. H. Simonds for helpful discussions. We also thank M. Blander, J. Larimer and D. Phinney for helpful reviews. This work was supported by the National Aeronautics and Space Administration through grants NGR 14-001-249 (to L. Grossman) and NGL 14001-169 (to R. N. Clayton), the National Science Foundation through grant EAR-7823420 and the Alfred P. Sloan Foundation.

\section{REFERENCES}

Allen J. M., Grossman L., Davis A. M. and Hutcheon I. D. (1978) Mineralogy, textures and mode of formation of a hibonite-bearing Allende inclusion. In Proc. Lunar Planet. Sci. Conf. 9th. pp. 1209-1233. Pergamon.

Arnett W. D. and Wefel J. P. (1978) ${ }^{26} \mathrm{Al}$ production from a stellar evolutionary sequence. Astrophys. J. (Lett.) 224, L139-L142.

Bakale D. K., Colby B. N. and Evans C. A. (1975) High mass resolution ion microprobe mass spectrometry of complex matrices. Anal. Chem. 47, 1532-1536.

Banner A. E. and Stimpson B. P. (1975) A combined ion probe/spark source analysis system. Vacuum 24, 511 . 517.

Beckett J. R., MacPherson G. J. and Grossman L. (1980) Major element compositions of coarse-grained Allende inclusions (abstr.). Meteoritics 15, 263.

Blander M. and Fuchs L. H. (1975) Ca-Al-rich inclusions in the Allende meteorite: evidence for a liquid origin. Geochim. Cosmochim. Acta 39, 1605-1619.

Blander M. and Katz J. L. (1967) Condensation of primordial dust. Geochim. Cosmochim. Acta 31, 1025. 1034.

Boynton W. V., Frazier R. M. and Macdougall J. D. (1980) Identification of an ultra-refractory component in the Murchison meteorite. In Lunar and Planetary Science $X I$, pp. 103-105. Lunar and Planetary Institute.

Cameron A. G. W. (1979) On the origin of asteroids. In Asteroids (ed. T. Gehrels), pp. 992-1007. University of Arizona Press.

Cameron A. G. W. and Pine M. R. (1973) Numerical models of the primitive solar nebula. Icarus 18, 407-450.

Catanzaro E. J., Murphy T. J., Garner E. L. and Shields W. R. (1966) Absolute isotopic abundance ratios and atomic weight of magnesium. J. Res. Nat. Bur. Stand. 70A, 453-458. 
Clayton D. D. (1979) Supernovae and the origin of the solar system. Space Sci. Rev. 24, 147-226.

Esat T. M., Papanastassiou D. A. and Wasserburg G. J. (1980) The initial state of ${ }^{26} \mathrm{Al}$ and ${ }^{26} \mathrm{Mg} /{ }^{24} \mathrm{Mg}$ in the early solar system. In Lunar and Planetary Science XI, pp. 262-264. Lunar and Planetary Institute.

Fuchs L. H., Oisen E. and Jensen K. (1973) Mineralogy, mineral chemistry, and composition of the Murchison (C2) meteorite. Smithsonian Contrib. Earth Sci. 10. $35 \mathrm{p}$.

Grossman L. (1972) Condensation in the primitive solar nebula. Geochim. Cosmochim. Acta 36, 597-619.

Grossman L. (1975) Petrography and mineral chemistry of Ca-rich inclusions in the Allende meteorite. Geochim. Cosmochim. Acta 39, 433-454.

Grossman L. (1980) Refractory inclusions in the Allende meteorite. Ann. Rev. Earth Planet. Sci. 8, 559-608.

Grossman L., Davis A. M., Olsen E. and Santoliquido P. M. (1977) Chemical studies of condensates in the Murchison Type 2 carbonaceous chondrite. In Lunar and Planetary Science VIII, pp. 377-379. Lunar and Planetary Institute.

Hutcheon I. D. (1981) Ion probe $\mathrm{Mg}$ isotopic measurements of Allende inclusions. In Symposium on Nuclear and Chemical Dating Techniques, in press. American Chem. Soc.

Keil K. and Fuchs L. H. (1971) Hibonite $\left[\mathrm{Ca}_{2}(\mathrm{Al}, \mathrm{Ti})_{24} \mathrm{O}_{3 \mathrm{H}}\right]$ from the Leoville and Allende chondritic meteorites. Earth Planet. Sci. Lett. 12, 184-190.

Keil K., Prinz. M., Planner H. N.. Skaggs S. R., Dowty E. Neison L. S., Richardson N. L. and Blander M. (1973) A qualitative comparison of textures in lunar chondrules and $\mathrm{CO}_{2}$ laser-formed synthetic chondrule-like spherules. University of New Mexico Institute of Meteoritics Spec. Pub. No. 7. $16 p$

Kieffer S. W. (1975) Droplet chondrules. Science 189, 333 340.

Kieffer S. W. and Simonds C. H. (1980) The role of volatiles and lithology in the impact cratering process. Rev. Geophys. Space Phys. 18, 143182.

Kurat G. (1970) Zur Genese der Ca-Al-reichen Einschlüsse im Chondriten von Lancé. Earth Planet. Sci. Lett. 9, $225-231$

Larimer J. W. and Anders E. (1970) Chemical fractionations in meteorites-III. Major element fractionations in chondrites. Geochim. Cosmochim. Acta 34, 367-387.

Lattimer J. M. and Grossman L. (1978) Chemical condensation sequences in supernova ejecta. Moon and Planets 19, 169-184.
Lee T. (1979) New isotopic clues to solar system formation. Rev. Geophys. Space Phys. 17, 1591-1611.

Lee T., Papanastassiou D. A. and Wasserburg G. J. (1976) Demonstration of ${ }^{26} \mathrm{Mg}$ excess in Allende and evidence for ${ }^{26} \mathrm{Al}$. Geophys. Res. Lett. 2, 109-112.

Macdougall J. D. (1979) Refractory element rich inclusions in CM meteorites. Earth Planet. Sci. Lett. 42, 1-6.

Macdougall J. D. and Phinney D. (1979) Magnesium isotopic variations in hibonite from the Murchison meteorite: an ion microprobe study. Geophys. Res. Lett. 6, 215218.

MacPherson G. J. and Grossman L. (1981) A once-molten, coarse-grained Ca-rich inclusion in Allende. Earth Planet. Sci. Lett. 52, 16-24.

MacPherson G. J, Bar-Matthews M., Tanaka T., Olsen E. and Grossman L. (1980) Refractory inclusions in Murchison: recovery and mineralogical description. In Lunar and Planetary Science XI, pp. 660-662. Lunar and Planetary Institute.

Marvin U. B., Wood J. A. and Dickey J. S. Jr. (1970) CaAl-rich phases in the Allende metcoritc. Earth Planet. Sci. Lett. 7, 346-350.

Morey G. W. (1964) Phase-equilibrium relations of the common rock-forming oxides except water. Data of reochemistry, Chapter L. U.S. Geol. Survey Prof. Paper 440-L. 158 p.

Nelson L. S., Blander M., Skaggs S. R. and Keil K. (1972) Use of a $\mathrm{CO}_{2}$ laser to prepare chondrule-like spherutes from supercooled molten oxide and silicate droplets. Earth Planet. Sci. Lett. 14, 338-344.

Russell W. A., Papanastassiou D. A. and Tombrello T. A. (1978) $\mathrm{Ca}$ isotope fractionation on the earth and other solar system materials. Geochim. Cosmochim. Acta 42, $1075-1090$.

Steele I. M., Hutcheon I. D., Solberg T. N., Smith J. V. and Clayton R. N. (1977) Effect of energy selection on quantitative analysis in secondary ion microanalysis. Int. J. Mass Spectrom. Ion Phys. 23, 293-305.

Steele I. M., Hervig R. L., Hutcheon 1. D. and Smith J. V. (1981) Ion microprobe techniques and analyses of olivine and low-Ca pyroxene. Amer. Mineralogist 66, $526-546$.

Tanaka T., Davis A. M., Hutcheon I. D., Bar-Matthews M., Olsen E., MacPherson G. J. and Grossman L. (1980) Refractory inclusions in Murchison: chemistry and $\mathrm{Mg}$ isotopic composition. In Lunar and Planetary Science XI. pp. 1122-1124. Lunar and Planetary Institute.

Wasserburg G. J., Lee T. and Papanastassiou D. A. (1977) Correlated $\mathrm{O}$ and $\mathrm{Mg}$ isotopic anomalies in Allende inclusions: II. Magnesium. Geophys. Res. Lett. 4, 299--302. 